\title{
Factors Affecting Tourist Satisfaction with Theatrical Performances: A case study of The Romance of the Song Dynasty in Hangzhou, China
}

\author{
Hanqun Song \\ $\&$ \\ Catherine Cheung
}

School of Hotel and Tourism Management,

The Hong Kong Polytechnic University

Accepted by International Journal of Tourism Research

\begin{abstract}
This study, for the first time, attempts to explore the factors affecting tourist satisfaction with a theatrical performance, The Romance of the Song Dynasty in Hangzhou, China. Four factors are identified to have affected tourist satisfaction: "Performance," "Venue Environment," "Service," and "Stage Facilities". These theatrical performance factors are examined to assess the relative influence on tourist overall satisfaction. Tourists have the highest satisfaction with "Stage Facilities" among all factors, however, "Service" is the most influential predictor of tourist overall satisfaction. Tourist demographic and travel characteristics towards these four theatrical performance factors reveal several significant differences. Discussions and implications are provided to theatre operators to improve tourist satisfaction with theatrical performance not only in Hangzhou, but also in the whole China.
\end{abstract}

Keywords: Tourist Satisfaction; Theatrical Performance; The Romance of the Song Dynasty; China 


\section{Introduction}

In the early stage of China's tourism industry, tourists travel mainly "for sightseeing", but nowadays, they prefer to "enjoy the travel experience" (Qiao, 2010). Pine and Gilmore (1999) mentioned that show/performance, served as an activity which makes tourists delight, could be used in designing tourists' rich experience. In China, theatrical performance, a product of tourism and cultural industries, could highly enhanced tourists' experiences during their travel ( $\mathrm{Li}$, Zhang and $\mathrm{Lu}, 2005)$. China's Ministry of Culture and National Tourism Administration highly encourage the incorporation of the performing arts into the tourism industry, and promote the development of theatrical performance (Central People's Government of the People's Republic of China, 2009). Theatrical performance combines the performing arts with high-technology facilities, and in some cases, beautiful natural surroundings (Shanghai Daily, 2006). Many destinations strongly support and promote the development of theatrical performances, which have developed fast in recent years (Zhuge and Cui, 2005). It is predicted that theatrical performance will become an important phenomenon in China's tourism industry (Dou, 2009).

Theatrical productions involved 17.6 thousand professional and amateur performers and 167 million audience members in China in 2007 (Wei, 2007). The economic impact of theatrical performance on a destination can be seen from The Impression of Liusanjie, which is directed by Chinese director Zhang Yimou in 2004. The performance increased the gross domestic product (GDP) of Yangshuo County in Guilin by more than 10\%, and increased the length of stay of tourists in the County by eight hours per person (Wang, 2008). In 2008, three hundred large-scale theatrical performances all over China generated more than RMB3 billion in the tourist attractions (Xin Jing News, 2008).

In China, theatrical performances can be categorized into five types (Qiao, 2010). Type 1: Large-scale outdoor theatrical performance. In Chinese Pin Yin, this type of performance is named as "Shijing" theatrical performance, which means performances are staged on a natural environment, such as rivers, lakes, valleys, etc., rather than in a theatre. The Impression of Liusanjie is the first outdoor theatrical performance, which is firstly created by Zhang Yimou in 2004. Nowadays, there are several popular outdoor theatrical performances in China. Type 2: Ethnic and folklore theatrical performance. This type of performance is designed and developed from the minority ethnic culture, folk custom, and local culture. There are many ethnic and folklore theatrical performances in the western part of China where the minority ethnics lived. There are largest numbers of this type of performance, partly because the production cost is cheaper compared to the large-scale outdoor theatrical performances. Type 3: Artistic performance. This type of theatrical performance is designed from historical events, and literary works. For instance The Song of Eternal Sorrow is revised and developed from The Song of Eternal Sorrow, a narrative poetry by Tang poet Bai Juyi; Type 4: Interactive theatrical performance. This type of performance focuses on the interactive activities between audiences and performers, such as Fenghuang Campfire Party. Type 5: Commercial theatrical performance. This type of 
performance is mainly designed to meet high tourists demand. For example, The Legend of Kung $F u$ targeted at international tourists, and presented them with a story of Kung Fu. It should be noted that some of the theatrical performances are belonging to two types; for instance, The Song of Eternal Sorrow belongs to both Type 1 and Type 2, because the performance is staged outdoors, and the storyline is revised from a literary work. Selected theatrical performances of these five types are shown in Table 1.

*******Please Insert Table 1 Here $* * * * * *$

Other theatrical performances categorization suggested by Song and Cheung (2010) uses criterions such as venue location and performers number. Theatrical performances can be divided into two types: indoors and outdoors. Some live shows are performed outdoors near hills, rivers or lakes. Examples include The Impression of Liusanjie, The Impression of Lijiang, The Impression of West Lake, The Song of Eternal Sorrow and Zen Music Shaolin Grand Ceremony, whereas indoor performances of well-known productions that are staged in a theatre include The Romance of the Song Dynasty, The Night of West Lake and The Legend of Kung $\mathrm{Fu}$. Using the number of performers as criterion, small theatrical performances feature one or two performers and large-scale live performances involve a hundred to more than 300 performers.

Theatrical performance, show, or live entertainment usually appears in casino studies (d'Hauteserre, 2000; Loi, 2008). McCleary, Lattimer, Clemenz, and Weaver (2008) suggested that utilizing performing arts such as jazz, opera, musical plays, non-musical plays, and dance can help restaurants to build a positive image in the community. They found respondents in their study had a favorable attitude toward businesses that support art performance in restaurants. Hughes (1998) examined the influence of theatre on tourism in London, and found that theatre is regarded as a significant factor in the choice of the city as a tourist destination. Even though some of the researches on theatrical performances can be found, it is rather limited. Pearce (2008) advocated that further research can be conducted in the theatrical performance-specific area. He also recommended tourism researchers to study small specialist groups of theatrical performance in niche locations (Pearce, 2008).

In China, studies on theatrical performance have mainly focused on general introduction and description of the popular phenomenon (Li, Zhang and Lu, 2005; Xu, 1998; Wei, 2007). However, very few research, e.g., Chen, Bai, Qiao and Park, 2008; Song and Cheung, 2009; 2010, explore the significance of theatrical performance using a marketing perspective. In order to further the research of Song and Cheung (2009), the present study uses The Romance of the Song Dynasty in Hangzhou, China as a case study to explore factors affecting tourist satisfaction with the theatrical performance.

The Romance of the Song Dynasty, an indoor theatrical performance, which is staged every day at the Grand Theatre of Song Dynasty Town, situated at the southern-west part of West Lake scenic area. As a tourist attraction in Hangzhou, Song Dynasty Town is the first largest theme park featuring the civilization of Song Dynasty (A.D.960-1279) in China 
(Song Dynasty Town, 2010). The Romance of the Song Dynasty is of one hour's duration, and tends to be a spectacular theatrical production. It is different from traditional performances such as Peking opera, or other local opera in China, because theatrical performances demonstrated a variety of arts rather than traditional opera, and The Romance of the Song Dynasty, staged at a tourist attraction, targets at tourists. Since Hangzhou is used to be the capital of Kingdom of Wuyue (A.D. 907-978) and Southern Song Dynasty (A.D. 1127-1279), there are ample historical stories about Hangzhou. This city is also famous for its local culture such as silk culture and Longjing tea culture. In addition, Chinese love stories, such as Legend of the White Snake, and The Butterfly Lovers, are all highly associated with Hangzhou. In The Romance of the Song Dynasty, the historical stories, local culture, and Chinese love stories are demonstrated by dancing, acrobatics, folk songs, sword fights, and horse ridings. It should be noted that impressive high technology such high-definition screen, laser, fire and waterfall are also implemented and displayed in this theatrical performance (Pan, 2009; People's Daily, 2009). All of these make The Romance of the Song Dynasty one of the three most famous shows in the world. It has attracted more than 20 million tourists since 1994 (Song Dynasty Town, 2010).

The primary objectives of this study are to:

1. Explore the factors affecting tourist overall satisfaction with The Romance of the Song Dynasty;

2. Assess the relative influence of theatrical performance factors on tourist overall satisfaction; and

3. Examine the relationship between tourists' demographic and travel characteristics with the theatrical performance factors.

\section{Literature Review}

\section{Factors Affecting Tourist Satisfaction}

Customer satisfaction is a post-consumption evaluation that customers make when the consumption experience either meets or exceeds expectations (Morrison, 2010). Tourist satisfaction is a well-established, long-standing research area explored by marketing researchers (Yuksel and Yuksel, 2002). Kozak (2001) summarizes four approaches to analyze tourist satisfaction: expectation-performance, importance-performance, disconfirmation approach, and performance approach. Oh and Parks (1997) identified at least nine theories of customer satisfaction underlining the previous studies: expectancy disconfirmation; assimilation or cognitive dissonance; contrast; assimilation contrast; equity; attribution; comparison level; generalized negativity; and value.

There are many tourism and hospitality studies of factors affecting the level of tourist satisfaction. These studies can be viewed from two perspectives: theoretical perspective and practical perspective. From a theoretical perspective, Bigné, Andreu and Gnoth (2005) found that the pleasure and arousal dimensions positively influence tourist satisfaction. Other studies also supported the idea that there is a relationship between emotion and 
satisfaction (Phillips and Baumgartner, 2002; Rojas and Camarero, 2008; Westbrook and Oliver, 1991). In addition, personal values are confirmed as a direct antecedent of customer satisfaction by Chen and Chen (2010), and Gallarza and Saura (2006). Perceived past experience quality is also regarded as a direct determinant of satisfaction (Chen and Chen, 2010; Rojas and Camarero, 2008).

From a practical perspective, especially in the destination context, tourist satisfaction can be affected by: lodging, food, shopping, attractions, activities and events, environment, accessibility, price, culture, climate and image, nature, lifestyle, history, service, tourist facility, sanitation, nightlife, availability of English language, and value for money (Chi and Qu, 2008; Heung and Cheng, 2000; Heung and Qu, 2000; Kozak and Rimmington, 2000). In previous tourist attraction studies, ease of access, ticket issue, level and variety of prices, services, safety, and employees were found to have affected tourist satisfaction (Mazanec, 2006; Matzler, Füller, Renzl, Herting and Späth, 2008). In the hospitality research, service, food, menu diversity, hygiene, convenience and location, noise, service speed, price and value, facilities, and atmosphere were also found to affect tourist satisfaction (Liu and Jang, 2009; Yuksel and Yuksel, 2002).

\section{Theatrical Performance}

Limited studies on theatrical performance are found in the tourism literature. Song and Cheung (2009) defined theatrical performances as large-scale live performances designed for tourists and are staged indoors or outdoors. Theatrical performance research has been studied previously by researchers in the tourism entertainment context (Hughes, 2000; Hughes and Allen, 2008; Pearce, 2008). Ryan and Collins (2008) firstly analyzed the construction of theatre entertainment with the examination of An Eastern Odyssey in Japan. They stated that within a trilogy of fantasies, including production, the nature of Huis Ten Bosch (a theme park in Nagasaki Prefecture that recreates the Netherlands), and a financial fantasy, An Eastern Odyssey becomes itself a metaphor for most post-modern tourism.

In China, some studies on theatrical performance explore the authenticity of the performing arts in the tourism industry (Li, Hymiti and Li, 2009; Rong, 2009; Tian and Bao, 2004). Chen et al., (2008) explored tourist satisfaction with a theatrical performance, Zen Music Shaolin Grand Ceremony, by using three perspectives namely: traditional, education, and fascination. Recently, Song and Cheung (2009) are the first to explore the theatrical performance attributes. By using four focus group discussions, they identified 34 theatrical performance attributes affecting tourist satisfaction, which could be categorized into five dimensions: stage, performing, theatre environment, service, and customer-related categories (Song and Cheung, 2009).

\section{Methodology}

\section{Questionnaire Design}


To meet the objectives of the study, a survey questionnaire was designed, consisting of the following three sections: (1) theatrical performance attributes, (2) tourist overall satisfaction, (3) tourist demographic and travel characteristics.

The first section of the questionnaire consists of 31 theatrical performance attributes, for which tourists are asked to indicate their satisfaction level. These 31 attributes are generated from two stages, which include a review of relevant literature and an item-screening test. In stage 1, a total of 49 theatrical performance attributes are generated from previous studies. Among them, 34 attributes are generated from Song and Cheung's (2009; 2010) study, and the remaining 15 attributes are developed from other studies (Hede et al., 2004; Liu and Jang, 2009; Matzler et al., 2008; Mazanec, 2006; Tian and Bao, 2005; Yuksel and Yuksel, 2002). In stage 2, a total of 35 academics, travel agency managers, as well as tourists were invited to participate in the item-screening test in May 2009. The item-screening procedure follows Chu and Choi's (2000) method to reduce the number of attributes. On-site data collection and email survey were conducted for the convenience to contact the target participants. Respondents were asked to rate the level of representativeness of 49 theatrical performance attributes based on a 7-point Likert scale. After the careful screening analysis and taken the advice from academic professionals, 31 out of the 49 attributes were selected. In the main survey, these 31 theatrical performance attributes were used to measure tourist satisfaction level in a 7-point Likert scale with 1 being "Very dissatisfied" and 7 being "Very satisfied".

The second section consists of constructs on tourist overall satisfaction. Numerous studies used a summative overall item to measure satisfaction (Bloemer and Ruyter, 1998; Bolton and Lemon, 1999; Hsu, 2000; 2003; Hsu and Kang, 2007). Thus, in this study, tourist overall satisfaction with theatrical performance is evaluated by a single question, "What is your overall satisfaction with The Romance of the Song Dynasty?" in a 7-point Likert scale with 1 being "Very dissatisfied" and 7 being "Very satisfied".

In the last part of the questionnaire, tourist demographic and travel characteristics variables are selected from previous literature (Hsu and Kang, 2007; Huang, 2007). Tourist demographic variables are: gender, age, marital status, occupation, education, and personal monthly income. Pattern of travel, purpose of travel, and repeat visit status are identified as travel characteristics variables.

The Chinese questionnaire was edited and proof-read by two researchers, who are both proficient in English and Chinese, to ensure the accuracy of the items translated from English. Prior to the main survey, a pilot test with 10 Master of Science students from a local university was undertaken during the period of June 2009. After the pilot test, slight revisions of the wordings were made to ensure the questions are comprehensible to the respondents.

\section{Data Collection}


The main survey of the study was conducted at Song Dynasty Town in Hangzhou, China, from 11 August to 17 August 2009. An on-site questionnaire survey was conducted at four locations in Song Dynasty Town, including the exit of the Grand Theatre, Central Square, Fanlou Restaurant, and Sun's Family Restaurant. One of the authors and three assistants who were tour guides invited tourists who have watched The Romance of the Song Dynasty to participate in the research. One of the authors used to be a tour guide in China, has watched all of the performances in the first day of the research. It should be noted that all of the day and night performances are the same in this study. Tourists who were resting or waiting for dinner in one of the four locations as mentioned were targeted and invited to take part in the main survey. To ensure the participant is qualified to participate in the study, they were firstly asked a question of "Have you just watched The Romance of the Song Dynasty?" If the answer was "Yes", then the tourist was invited to participate in the survey. It takes about 10 minutes for each participant to complete a questionnaire. Data were collected from 3:30pm to 9:00pm, the day and night performances were the same, the first performance started at $2: 30 \mathrm{pm}$, and the last performance ended at 9:30pm. The data collection has to be completed before 9:00pm because of the insufficient lighting facilities in the area and tourists' unwillingness to participate in the survey after watching the performance at a very late hour. The participants were reminded to return the completed questionnaire to the researcher/assistants or to the ticketing office in Song Dynasty Town. In total 500 questionnaires were sent out, and 242 were usable with a $48.4 \%$ usable rate.

\section{Data Analysis}

The software SPSS 16 was used for the main study data analysis. Factor analysis was implemented to identify the underlying dimensions of tourist overall satisfaction with the thirty one theatrical performance attributes (Objective 1). Multiple regression analysis was used to assess the influence of underlying theatrical performance factors on tourist overall satisfaction (Objective 2). In order to explore the relationship between tourist demographic and travel characteristic variables with theatrical performance factors, independent samples t-test and ANOVA were conducted (Objective 3).

\section{Result}

\section{Respondent profile and tourist overall satisfaction}

Respondents' demographic profile and travel characteristics are presented in Table 2. Female respondents (60.3\%) outnumbered their male counterparts (39.7\%). Most respondents were relatively young. About $83 \%$ of the respondents were under the age of 40 , with almost half of the sample (48.8\%) falling into the age category of 19-29. In terms of marital status, $51.2 \%$ of the respondents were single, while $48.8 \%$ were married. Around $27.3 \%$ of the respondents were clerk/white-collar workers, followed by others and students with $19.8 \%$ and $18.6 \%$ respectively. Almost $35.5 \%$ of the respondents had college education, while one-third of the respondents $(29.3 \%)$ had a university education. In terms 
of personal monthly income, $46.7 \%$ respondents had an income with RMB1,001-3,000, and around $25.6 \%$ respondents had an income with RMB3,001-5,000.

In terms of travel characteristics, package tourists dominated the pattern of travel with $75.6 \%$, while the rest of the respondents $(24.4 \%)$ were individual tourists. In terms of purpose of travel, only $11.6 \%$ respondents traveled for business, and most of the respondents $(88.4 \%)$ were leisure tourists. First-time visitors accounted for $83.9 \%$ of the total respondents, while the rest $16.1 \%$ were repeat visitors.

*******Please Insert Table 2 Here $* * * * * *$

Almost $80.6 \%$ of the respondents were satisfied with the theatrical performance they had watched, whereas only $2.5 \%$ respondents were dissatisfied. The mean rating of the tourists' overall satisfaction score is $6.11(\mathrm{Std}$. Dev $=.976)$, indicating that the respondents are in general satisfied with the theatrical production.

\section{Factors affecting tourist satisfaction with theatrical performance}

A principal components factor analysis with VARIMAX rotation was conducted to extract underlying factors and reduce the items pool with 31 attributes in the main survey. Kaiser-Meyer-Oklin (KMO) of the study is 0.931, and the Bartlett's test of Sphericity is 5632 with significance lower than .000 , which supported the use of factor analysis for these items (Hair, Black, Babin, Anderson and Tatham, 2006; Tabachnick and Fidel, 1996). The factors derived following Hair et al., (2006) suggestions that eigenvalue should be higher than 1.0 and factor loading should be .50 or above .50 . After the factor analysis, two attributes, item 1: Content of the performance, and item 17: Punctual start of performance, are removed as their factor loadings are lower than .50 (Hair et al., 2006). Results of factor analysis as shown in Table 3 reveal that 29 out of 31 attributes are condensed into four dimensions, including: Factor 1: Performance; Factor 2: Venue Environment; Factor 3: Service; and Factor 4: Stage Facilities.

*******Please Insert Table 3 Here $* * * * * *$

Table 4 summarizes the four factors affecting tourist overall satisfaction with theatrical performance based on their mean values. Factor 4 "Stage Facilities" had a mean value of 6.42 , which was the highest among the four factors, implying that tourists had the highest satisfaction level towards stage facilities of theatrical performance in the study. Factor 1 "Performance" followed with a mean value of 6.32, which also implied the higher satisfaction level from tourists. Factor 3 "Service" with a mean value of 5.87, ranked the third, and Factor 2 "Venue Environment" had the lowest factor mean of 5.72, implying that tourists was least satisfied with the venue environment of theatrical performance compared with other factors.

******Please Insert Table 4 Here $* * * * * *$ 


\section{Relative influence of theatrical performance factors on tourist overall satisfaction}

A multiple regression analysis was employed using tourist overall satisfaction as a dependent variable, and four theatrical performance factors as independent variables. Table 5 reports the results of the regression analysis. As shown by the correlation coefficient $(\mathrm{R}=.643)$, it is noted that tourists have a positive and high overall satisfaction level with the four theatrical performance factors. In addition, the coefficient of determination $\left(R^{2}\right)$ is .414 , suggesting that more than $41.4 \%$ of the variation of tourist overall satisfaction is explained by the four factors. Lastly, the F ratio, which indicates whether the results of the regression model would have occurred by chance, has a value of 34.594 (sig= .000), suggesting that the regression model could have not occurred by chance. The above-mentioned $R, \mathrm{R}^{2}$, and $\mathrm{F}$ ratio reveal that the regression model has a satisfactory level of goodness of fit in predicting the variance of tourist overall satisfaction in relation to the four theatrical performance factors.

\section{*****Please Insert Table 5 Here*****}

With regard to overall satisfaction, all of the four theatrical performance factors are significant predictors. Factor 3 "Service" (Beta $=.368, \mathrm{p}<.05)$ is the best predictor, factor 2 "Performance" $($ Beta $=.353, \mathrm{p}<.05)$ is regarded as the second most significant contributor, "Venue Environment" (Beta $=.349, \mathrm{p}<.05)$ is the third important predictor, and the least important contributor is "Stage Facilities" (Beta $=.184, \mathrm{p}<.05)$. Therefore, "Service" was selected as the best predictor constituted $36.8 \%$ to the dependent variable which highly affects overall satisfaction with theatrical performance.

\section{Demographic and travel characteristic differences towards theatrical performance factors}

Table 6 shows the findings of the differences between tourist demographic and travel characteristics towards theatrical performance factors. In terms of "Performance," significant differences could be seen in Gender $(\mathrm{p}=.048, \mathrm{~F}=-0.218)$, males scored significantly higher than females. With respect to "Venue Environment," significant differences could be found in Gender ( $\mathrm{p}=.014, \mathrm{~F}=-1.579$ ), males scored significant higher than females. In terms of "Service," significant age difference is found in the Age category $(\mathrm{p}=.019, \mathrm{~F}=3.041)$. Results show that different age group had different perceptions toward "Service" factor. Tourists aged between 19 and 29 had significant higher mean scores than tourists aged between 40 and 49. In addition, in terms of Marital Status, single respondents scored significant higher than married respondents in "Service" $(p=.024, t=3.293)$.

\section{******Please Insert Table 6 Here*****}

\section{Discussion}


This study successfully identified the factors affecting tourist satisfaction with The Romance of the Song Dynasty in Hangzhou, China. The relative influence of theatrical performance factors on tourist overall satisfaction are examined. In addition, tourist demographic and travel characteristic differences towards theatrical performance factors are identified.

"Performance" refers to the issues of performers and performance. This factor had the second highest factor mean (6.32), indicating that tourists were very satisfied, and the multiple regression analysis indicated that it had second largest impact on tourist overall satisfaction. Some studies have confirmed that performance plays an important role in the level of tourist satisfaction (Hede et al., 2004; Song and Cheung, 2009; 2010; Tian and Bao, 2005), and professionalism of performers is a key to a successful theatrical performance (Cui, 2006). Pearce (2008) also claimed that a major source of audience admiration in live entertainment is likely to be that of the skill of the performers. In this study, "Performance" was rated rather high in this study. Tourists are, therefore, likely to pay attention on other aspects such as service, and venue environment, which may directly influence their overall satisfaction levels with the theatrical performance. It is interesting to find males have a significantly higher satisfaction with "performance" factor than females. This finding could be explained by Bendall-Lyon and Powers's (2002) study that female consumers commonly showed lower satisfaction than males, and females' satisfaction declined faster than males. Another reason may be the fact that females and males prefer different types of tourism and leisure activities (Junek, Binney and Winn, 2006; Sargent, Zillman and Weaver, 1998).

"Venue environment" refers to the environment where the theatrical performance is staged. This factor had the lowest mean rating (5.76), indicating that tourists were not very satisfied with it compared with other factors. There is an urgent need to improve the "Venue Environment" factor. It was an important determinant for tourist overall satisfaction based on the results of multiple regression analysis. The finding of "Venue environment" is considered as being important for tourist satisfaction, is consistent with other studies on tourism and hospitality (Hede et al., 2004; Matzler et al., 2008; Song and Cheung, 2009). In addition to the venue specific item, items such as seating, cleanliness, air and temperature, safety and security of the venue are also included in this factor. Males scored significantly higher than females towards "Venue Environment", this could be explained by the higher requirements of females than males towards hotel and tourism facilities (McCleary, Weaver and Li, 1994).

"Service" refers to the service issues in the theatrical performance. Tourists were not very satisfied with this factor, and the findings of multiple regression analysis indicated that it was the best predictor of tourist satisfaction. Previous research has shown that "Service" is regarded as the most influential antecedent to tourist satisfaction (Bitner, 1990; Choi and Chu, 2001; Cronin and Taylor, 1992; Rust and Oliver, 1994). Song and Cheung (2010) also found that service attributes could directly affect tourist satisfaction with theatrical performance in China. In this study, items such as service quality of the staff, ticket price/value for money, and suitable duration of the performance also coincided with the 
service attributes in Song and Cheung's (2010) study. Although tourists have very limited interaction with employees compared with guest contact employees in the hospitality industry such as hotels and restaurants, it should be noted that every tourist has several chances to contact front line at The Romance of the Song Dynasty. For individual tourists, they have to contact staff at the ticketing office of the Song Dynasty Town and also encounter staff at the entrance of the attraction. When they entered the attraction, they have to experience the service at another ticketing office and at the entrance of The Romance of the Song Dynasty show. In addition, they have a direct interaction with ushers of the theatre. Furthermore, some individual tourists may have inquiries at the information desk of the theatrical performance. For package tourists, they experienced the same service encounters similar to the individual tourist except for the service at the ticketing office, because their tickets were purchased by the tour guides. The importance of the service cited from Song and Cheung's (2010) study shows that "The quality of the service offered by the staff at the venue affected my level of satisfaction. Competent staff could answer my enquiry about the theatrical performance; however, some of them did not know much about the performance."

In terms of demographic impact, both tourists' age and marital status resulted in significant differences towards the "Service" factor. Tourists aged between 19 and 29 rated significantly higher than those aged between 40 and 49. In general, younger tourists were more satisfied with this factor when compared with middle aged tourists, whereas middle aged tourists were less satisfied with the service in the theatre. It might be due to the fact that middle aged tourists have higher expectations towards the service. Younger tourists might give more attention to the show, and have fewer expectations towards the service quality as well as the values for money of the price charged. In addition, single tourists scored statistically higher than married ones. In other words, married tourists were less satisfied with the service in the theatre. They might have higher expectation when the whole experience is a family activity.

"Stage Facilities" refers to the stage facilities and equipments on the stage, which had the highest mean value at 6.42 . This indicates that tourists had very high satisfaction levels towards this factor in this study. Nevertheless, this factor was the least important in determining tourist overall satisfaction. The tangible stage-related attributes always capture tourists' attention to the stage and the performance being played, these items played a great role in tourist satisfaction level. The results coincide with previous studies that the key to a successful theatrical performance is high standard stage facilities (Cui, 2006; Pan, 2009; People's Daily, 2009). Song and Cheung (2009) also concluded that stage facilities could affect tourist satisfaction with theatrical performance. Furthermore, Pearce (2008) suggested that the use of technology in theatre entertainment settings has flourished and the efforts nowadays are to create four-dimensional effects in viewing areas through the use of objects, water and special video screen.

\section{Conclusion and Recommendation}


This study addresses the gap in knowledge about tourist satisfaction with theatrical performances in China. Because of the scarcity of theatrical performance-specific research, this study, for the first time, enriches the literature by developing a measurement scale of theatrical performance attributes. Then, the factors affecting tourist satisfaction with theatrical performance are explored. They are: "Performance," "Venue Environment," "Service," and "Stage Facilities." Additionally, the theatrical performance factors are examined to assess the relative influence on tourist overall satisfaction. Results show that "Service" factor is the most influential determinant of tourist overall satisfaction. There are several significant differences between tourist demographic and travel characteristics differences with "Performance," "Venue Environment," and "Service" factors.

Based on the results of the study, recommendations and suggestions are given to the theatre operators to enhance their operations, management, and tourist satisfaction with The Romance of the Song Dynasty in Hangzhou, China. Theatre operators should maintain the strengths of "Performance," retaining its uniqueness and difference from others by presenting professionalism, unique dancing, music, and costumes. Theater operators could provide training programs to performers to improve their skills. Recruiting professional performers and inviting famous directors to design the performance are also an effective way to improve the standard of performance. As females have lower satisfaction levels than males, it is suggested that theatre operators should seek the opinions from female tourists. Improvement of the performance should be regularly made considering their feedback. However, it should be noted that redesign and modifying the performance should be based on the suggestions from both industry practitioners and tourists.

Given the lowest mean rating of "Venue Environment," theatre operators should improve the venue facilities, including seating, vision of the performance, cleanliness, safety and security, air and temperature conditions. Detailed practices for "Venue Environment" improvement should include: theatre seating should be re-designed for comfort. In addition, safety information should be clearly displayed in the venue; notices on safety and security described and shown on the tickets; careful and considerate service provided by the host of the venue; and more security staff arranged in the venue especially in peak seasons. Furthermore, extra cleaners should be arranged to clean the venue in peak seasons. Regarding the problems with behavior of other audience members (e.g., standing up or taking pictures in the performance), Song and Cheung (2010) claimed that it cannot be easily addressed as many Chinese tourists had this kind of behavior, nevertheless, notices and announcements could be used to remind the audience to refrain from these practices.

It is imperative for theatre operators or management teams to improve "Service" to enhance tourist satisfaction levels, which may eventually lead tourists to make subsequent revisits and recommendations as this factor is regarded as the most important contributor to tourist overall satisfaction. Detailed practices for "Service" improvement in the context should include: Service skills training should be provided to guest-contact employees to improve their skills in creating tourist satisfaction; Incentive and performance appraisal 
programs are to be used to encourage employees' outstanding service performance. Ticket price and duration of the performance should be readjusted to meet different market demands. All these service improvements could create a positive personal experience for tourists, who may communicate with their friends and relatives. This type of positive word-of-mouth is a good way to attract more tourists, leading to repeat patronage in the short term and enhancing the revenue and competitiveness in the long term. As identified in this study, tourists aged above 40, and those who are married, pay more attention to are the service in the venue, promotion strategies to these types of tourists can focused on the service enhancement of the performance.

The findings suggest that theatre operators should keep up or improve "Stage Facilities" to maintain tourist high satisfaction levels not only for The Romance of the Song Dynasty but also for others theatrical plays in the whole China. In China, theatrical performances have developed rapidly recently; and many theatre organizers have made considerable investment in multi-media technology of the stage facilities (Shanghai Daily, 2006). Theatre operators should, therefore, enhance the stage facilities and equipment, such as: water, fire, lighting, stage decoration, and high-definition scenery or screen, to enhance the attractiveness of the performance. High technology can also be utilized to enlarge or reduce the size of the stage during the performance.

As a model of China's theatrical performance, The Romance of the Song Dynasty has attracted many media's attention to introduce its successful experience (Pan, 2009). There are three hundred large-scale theatrical performances in China (Xin Jing News, 2008); even almost every "International Tourism City" in China now stages theatrical performances (Zhuge and Cui, 2005), however most of theatrical performances have homogeneity and similarity, such as shared the similar culture background, performing style, high-technology equipments, etc. (Qiao, 2010). Therefore, findings of this study can be served as a benchmark to other theatrical performances in China to enhance the operations and management ranging from "Performance," "Venue Environment," "Service," to "Stage Facilities."

This study provides important theoretical contributions and practical implications. Nevertheless, it should be acknowledged that this research has unavoidable limitations. First, all of the respondents in the research are mainland Chinese; the target market of some theatrical performances is international tourists. There might be significant differences between domestic tourists and international tourists' perceptions towards the theatrical performance attributes. International tourist satisfaction with theatrical performances should be examined in the future. Second, this research mainly focuses on the tangible attributes of theatrical performance to explore the factors affecting tourist satisfaction; it is suggested that future research should explore tourist perception on theatrical performances' intrinsic characteristic, such as cultural origin, performance style, and storyline, which could emphasize the theatrical performance as a dazzling spectacular of presentation and individual uniqueness. 


\section{References}

Bendall-Lyon, D. \& Powers, T. L. (2002). The impact of gender differences on change in satisfaction over time. Journal of Consumer Marketing, 19(1), 12-23.

Bigné, J. E., Andreu, L., \& Gnoth, J. (2005). The theme park experience: An analysis of pleasure, arousal and satisfaction. Tourism Management, 26(6), 833-844.

Bitner, J. M. (1990). Evaluating service encounters: The effects of physical surroundings and employee responses. Journal of Marketing, 54(2), 69-82.

Bloemer, J., \& Ruyter, K. (1998). On the relationship between store image, store satisfaction and store loyalty. European Journal of Marketing, 32(5/6), 499-513.

Bolton, R. N., \& Lemon, K. N. (1999). A dynamic model of customers' usage of services: Using as an antecedent and consequence of satisfaction. Journal of Marketing Research, 36(2), 171-186.

Central People's Government of the People's Republic of China. (2009). Guides and suggestions for the cooperation of culture industry and tourism industry from China Ministry of Culture and China National Tourism Administration. Retrieved September 29, 2009, from http://big5.gov.cn/gate/big5/www.gov.cn/zwgk/200909/15/content_1418269.htm.

Chen, C. F., \& Chen, F. S. (2010). Experience quality, perceived value, satisfaction and behavioral intentions for heritage tourists, Tourism Management, 31(1), 29-35.

Chen, N., Bai, K., Qiao, G., \& Park, K. (2008). A demonstrative study on inbound tourists' satisfaction with Chinese traditional cultural tourism product: A case on Zen Music Shaolin Grand Ceremony. Tourism Tribune, 23(6), 24-29, (in Chinese).

Chi, C. G., \& Q, H. (2008). Examining the structural relationships of destination image, tourist satisfaction and destination loyalty: An integrated approach. Tourism Management, 29(4), 624-636.

Chu, R. K., \& Choi, T. (2000). An Importance-Performance Analysis of hotel selection factors in the Hong Kong hotel industry: A comparison of business and leisure travelers. Tourism Management, 21(4), 363-377.

Cronin, J. J. \& Taylor, S. A. (1992). Measuring service quality: A reexamination and extension. Journal of Marketing, 56(July), 55-68.

Cui, X. (2006). Creativity and development of tourism performance in Hengdian world studio. Retrieved November 18, 2009, from http://www.ccmedu.com/bbs45 12025.html.

d'Hauteserre, A. M. (2000). Lessons in managed destination competitiveness: the case of Foxwoods casino resort. Tourism Management, 21(1), 23-32.

Dou, Q. (2009). The current status and trend of China's tourist attractions development. In G. Zhang, D. Liu, \& R. Song (Eds.), China's tourism development analysis and forecast (pp. 153-161). Beijing: Social Science Academic Press.

Gallarza, M. G., \& Saura, I. G. (2006). Value dimensions, perceived value, satisfaction and loyalty: an investigation of university students' travel behavior. Tourism Management, 27(3), 437-452.

Hair, J. F., Black, W. C., Babin, B. J., Anderson, R. E., \& Tatham, R. L. (2006). Multivariate data analysis. Upper Saddle River, NJ: Pearson/Prentice Hall. 
Heung, V. C., \& Cheng, E. (2000). Assessing tourists' satisfaction with shopping in the Hong Kong Special Administrative Region of China. Journal of Travel Research, 38(4), 396-404.

Heung, V. C., \& Qu, H. (2000). Hong Kong as a travel destination: an analysis of Japanese tourists' satisfaction levels, and the likelihood of them recommending Hong Kong to others. Journal of Travel \& Tourism Marketing, 9(1), 57-80.

Hsu, C. H. (2000). Determinants of mature travelers' motorcoach tour satisfaction and brand loyalty. Journal of Hospitality and Tourism Research, 24(2), 223-238.

Hsu, C. H. (2003). Mature motorcoach travelers' satisfaction: A preliminary step toward measurement development. Journal of Hospitality and Tourism Research, 27(3), 291-309.

Hsu, C. H., \& Kang, S. K. (2007). CHAID-based segmentation: International visitors' trip characteristics and perceptions. Journal of Travel Research, 46(2), 207-216.

Huang, S. S. (2007). The effects of motivation, past experience, perceived constraint, and attitude on tourist revisit intention. Unpublished doctoral dissertation, The Hong Kong Polytechnic University.

Hughes, H. L. (1998). Theatre in London and the interrelationship with tourism. Tourism Management, 19(5), 445-452.

Hughes, H. (2000). Arts, Entertainment and Tourism. Oxford: Butterworth Heinemann.

Hughes, H., \& Allen, D. (2008). Entertainment and its significance in the holiday experience at UK seaside resort. Tourism Recreation Research, 33(2), 131-141.

Junek, O., Binney, W., \& Winn, S. (2006). All-female travel: What do women really want? Tourism, 54(1), 53-62.

Kozak, M. (2001). A critical review of approaches to measure satisfaction with tourist destinations. In J. A. Mazanec, G. I Crouch, J. R. Ritchie, \& A. G. Woodside (Eds.), Consumer psychology of tourism, hospitality and leisure (pp. 303-319). New York: CABI Publishing.

Kozak, M., \& Rimmington, M. (2000). Tourist satisfaction with Mallorca, Spain, as an off-season holiday destination, Journal of Travel Research, 38(3), 260-269.

Li, L., Zhang, H., \& Lu, J. (2005). The production mode of tourism performing art as a cultural industry: A case study of the theme park in Shenzhen Overseas Chinese Town. Tourism Science, 19(6), 44-51, (in Chinese).

Li, C., Hymiti, Y., \& Li, X. (2009). A study of factors influencing the authenticity of Uygur performances in Xinjiang. Journal of Xinjiang University, 37(1), 81-84, (in Chinese).

Liu, Y., \& Jang, S. (2009). Perceptions of Chinese restaurants in the U.S.: What affects customer satisfaction and behavioral intentions? International Journal of Hospitality Management, 28(3), 338-348.

Loi, K. I. (2008). Gaming and entertainment tourist destinations: A world of similarities and differences. Tourism Recreation Research, 33(2), 165-183.

Matzler, K., Füller, J., Renzl, B., Herting, S., \& Späth, S. (2008). Customer satisfaction with Alpine ski areas: The moderating effects of personal, situational, and product factors. Journal of Travel Research, 46(4), 403-413. 
Mazanec, J. A. (2006). Exploring tourist satisfaction with nonlinear structural equation modeling and inferred causation analysis. Journal of Travel \& Tourism Marketing, 21(4), 73-90.

McCleary, K. W., Weaver, P., \& Li, L. (1994). Gender-based differences in business travelers lodging preferences. Cornell Hotel and Restaurant Administration Quarterly, 35(1), 51-58.

McCleary, K. W., Lattimer, C. L., Clemenz, C. E., \& Weaver, P. A. (2008). From broadway to the Bistro: Partnering with the arts to attract upscale customers. International Journal of Hospitality Management, 27(2), 197-203.

Morrison, A. M. (2010). Hospitality and travel marketing ( ${ }^{\text {th }}$ ed.). Clifton Park, N.Y.: Delmar Cengage Learning.

Oh, H., \& Parks, S. (1997). Customer satisfaction and service quality: A critical review of the literature and research implications for the hospitality industry. Hospitality Research Journal, 20(3), 35-62.

Pan, N. (2009). The Romance of the Song Dynasty successfully builds up a cultural brand of theatrical performance in China. Retrieved January 6, 2010, from http://www.songcn.com/Article Show.asp?ArticleID=3206

Pearce, P. L. (2008). Tourism and entertainment: Boundaries and connections. Tourism Recreation Research, 33(2), 125-130.

People's Daily. (2009, June 26). The Romance of the Song Dynasty becomes the new attraction of Hangzhou. Retrieved January 10, 2010, from http://www.songcn.com/Article Show.asp?ArticleID=3178

Phillips, D. M., \& Baumgartner, H. (2002). The role of consumption emotions in the satisfaction response. Journal of Consumer Psychology, 12(3), 243-252.

Pine, B. J. \& Gilmore, J. H. (1999). The experience economy: Work is theatre and every business a stage. Boston: Harvard Business School Press.

Qiao, Q. (2010). An exploratory study of China's cultural performance market in tourism industry. Retrieved May 5, 2010, from http://www.cncci.org/jty.jsp?id=483

Rong, H. (2009). Interpretation of the authenticity of stage performance of folk custom tourism: A case study of Amazing Xiangxi, Journal of Huaibei Professional and Technical College, 8(4), 34-36, (in Chinese).

Rojas, C., \& Camarero, C. (2008). Visitors' experience, mood and satisfaction in a heritage context: Evidence from an interpretation center. Tourism Management, 29(3), 525-537.

Rust, R. T. \& Oliver, R. L. (1994). Service quality insights and managerial implications from the frontier. In R. T. Rust, \& R. L. Oliver (Eds.), Service quality: New directions in theory and practice (pp. 1-20). London: Sage.

Ryan, C., \& Collins, A. B. (2008). Entertaining international visitors: The hybrid nature of tourism shows. Tourism Recreation Research, 33(2), 143-149.

Sargent, S. L., Zillman, D., \& Weaver, J. B. (1998). The gender gap in the enjoyment of televised sports. Journal of Sport and Social Issues, 22(1), 46-64.

Shanghai Daily. (2006, November 8). Open-air blockbusters: The future of Chinese theatre? Retrieved March 21, 2009, from http://russian.china.org.cn/english/culture/188335.htm

Song, H., \& Cheung, C. (2009). Attributes affecting tourists' satisfaction and loyalty towards theatrical performance in China. Proceedings of 8th Asian Pacific forum for 
graduate students research in tourism (pp. 684-694). July 7-9, 2009 at Seoul, Korea.

Song, H., \& Cheung, C. (2010). Attributes affecting the level of tourist satisfaction with and loyalty towards theatrical performance in China: Evidence from a qualitative study. International Journal of Tourism Research, Retrieved May 12, 2010, from http://www3.interscience.wiley.com/cgi-bin/fulltext/123352782/PDFSTART

Song Dynasty Town. (2010). Introduction of the Song Dynasty Town and the Romance of the Song Dynasty. Retrieved April 22, 2010, from http://www.songcn.com/index.htm

Tabachnick, B. G., \& Fidell, L. S. (1996). Using Multivariate Statistics. New York, NY: Harper Collins College Publishers.

Tian, M., \& Bao, J. (2005). Tourists' perspectives on the authenticity of ethnic performance: A case study of Dai Minority in Xishuangbanna. Journal of Guilin Institute of Tourism, 16(1), 12-19, (in Chinese).

Wang, C. (2008). Insights from tourism marketing on outdoor theatrical performance: A case from The Impression of Liusanjie. Culture and History Vision (Theory), 49(1), 70-71, (in Chinese).

Wei, X. (2007, December 14). An review on tourism performance market in 2007. China Tourism News, 5-8, (in Chinese).

Westbrook, R. A., \& Oliver, R. L. (1991). The dimensionality of consumption emotion patterns and consumer satisfaction. Journal of Consumer Research, 18(1), 84-91.

Xin Jing News. (2008, December 24). A review on tourism performing industry in China. Retrieved March 23, 2009, from http://www.ask.com/web?o=14159\&l=dis\&vfr=1\&q=www\%2Epeople\%2Ecom\%2Ecn

$\mathrm{Xu}, \mathrm{J}$. (1998), Review of conference on theme parks and performing arts in China. Tourism Tribune, 13(5), 18-22, (in Chinese).

Yuksel, A., \& Yuksel, F. (2002). Measurement of tourist satisfaction with restaurant services: A segment-based approach. Journal of Vacation Marketing, 9(1), 52-68.

Zhuge, Y., \& Cui, F. (2005). Research on tourism performing product refinement strategy in China. Social Scientist, 115(5), 121-123, (in Chinese). 
Table 1: List of selected theatrical performances in China

\begin{tabular}{|c|c|c|}
\hline Name & Place & Founded Year \\
\hline The Impression of Liusanjie & Guilin, Guangxi Autonomous Region & 2004 \\
\hline The Impression of Lijiang & Lijiang, Yunnan Province & 2006 \\
\hline The Golden Age of Three Gorges & Yichang, Hubei Province & 2006 \\
\hline The Song of Eternal Sorrow & Xi'an Shaanxi Province & 2006 \\
\hline Four Seasons of Zhouzhuang & Suzhou, Jiangsu Province & 2007 \\
\hline The Impression of West Lake & Hangzhou, Zhejiang Province & 2007 \\
\hline Zen Music Shaolin Grand Ceremony & Dengfeng, Henan Province & 2007 \\
\hline Ancient Music of Song Dynasty & Kaifeng, Henan Province & 2008 \\
\hline Berthing on the Qinhuai River & Nanjing, Jiangsu Province & 2009 \\
\hline \multicolumn{3}{|c|}{ Type 2: Ethnic and folklore theatrical performance } \\
\hline Name & Place & Founded Year \\
\hline The Romance of the Song Dynasty & Hangzhou, Zhejiang Province & 1996 \\
\hline Colorful Guizhou Wind & Guiyang, Guizhou Province & 2005 \\
\hline Da He Show & Zhengzhou, Henan Province & 2007 \\
\hline Horizon & Guiyang, Guizhou Province & 2008 \\
\hline \multicolumn{3}{|l|}{ Type 3: Artistic performance } \\
\hline Name & Place & Founded Year \\
\hline Back to Tang Dynasty & Xi'an, Shaanxi Province & 2005 \\
\hline The Song of Eternal Sorrow & Xi'an, Shaanxi Province & 2006 \\
\hline Nine Songs & Wuhan, Hebei Province & 2009 \\
\hline \multicolumn{3}{|c|}{ Type 4: Interactive theatrical performance } \\
\hline Name & Place & Founded Year \\
\hline Fenghuang Campfire Party & Fenghuang, Hunan Province & NA \\
\hline Amazing Xiangxi & Zhangjiajie, Hunan Province & 2001 \\
\hline \multicolumn{3}{|c|}{ Type 5: Commercial theatrical performance } \\
\hline Name & Place & Founded Year \\
\hline Legend of Kung Fu & Beijing & 2004 \\
\hline ERA-Intersection of Time & Shanghai & 2006 \\
\hline
\end{tabular}

Note: Revised from Qiao (2010). 
Table 2 Demographic profile and travel characteristics of the respondents $(\mathrm{N}=242)$

\begin{tabular}{|c|c|c|c|}
\hline & & Frequency & Percentage \\
\hline \multirow[t]{2}{*}{ Gender: } & Male & 96 & $39.7 \%$ \\
\hline & Female & 146 & $60.3 \%$ \\
\hline \multirow[t]{5}{*}{ Age: } & Less than 19 & 20 & $8.3 \%$ \\
\hline & $19-29$ & 118 & $48.8 \%$ \\
\hline & $30-39$ & 64 & $26.4 \%$ \\
\hline & $40-49$ & 35 & $14.5 \%$ \\
\hline & 50 or above & 5 & $2.1 \%$ \\
\hline \multirow[t]{2}{*}{ Marital Status: } & Single & 124 & $51.2 \%$ \\
\hline & Married & 118 & $48.8 \%$ \\
\hline \multirow[t]{8}{*}{ Occupation: } & Businessperson & 16 & $6.6 \%$ \\
\hline & Civil servant & 14 & $5.8 \%$ \\
\hline & Teacher & 34 & $14 \%$ \\
\hline & Clerk/White-collar worker & 66 & $27.3 \%$ \\
\hline & Blue-collar worker & 18 & $7.4 \%$ \\
\hline & Retired & 1 & $0.4 \%$ \\
\hline & Student & 45 & $18.6 \%$ \\
\hline & Other & 48 & $19.8 \%$ \\
\hline \multirow[t]{5}{*}{ Education: } & Middle school or less & 21 & $8.7 \%$ \\
\hline & High school & 43 & $17.8 \%$ \\
\hline & Vocational college & 86 & $35.5 \%$ \\
\hline & 4 years of university & 71 & $29.3 \%$ \\
\hline & Postgraduate or above & 21 & $8.7 \%$ \\
\hline Personal Monthly & Less than RMB1,000 & 7 & $2.9 \%$ \\
\hline \multirow[t]{4}{*}{ Income: } & RMB1,001-3,000 & 113 & $46.7 \%$ \\
\hline & RMB3,001-5,000 & 62 & $25.6 \%$ \\
\hline & More than RMB5,000 & 23 & $9.5 \%$ \\
\hline & No income & 37 & $15.3 \%$ \\
\hline \multirow[t]{2}{*}{ Pattern of Travel: } & Tour package & 183 & $75.6 \%$ \\
\hline & Individual tour & 59 & $24.4 \%$ \\
\hline \multirow[t]{2}{*}{ Purpose of Travel: } & Business & 28 & $11.6 \%$ \\
\hline & Leisure & 214 & $88.4 \%$ \\
\hline Repeat Visit & First-time visitor & 203 & $83.9 \%$ \\
\hline Status: & Repeat visitor & 39 & $16.1 \%$ \\
\hline
\end{tabular}


Table 3 Factors affecting tourist satisfaction with theatrical performance

\begin{tabular}{|c|c|c|c|c|c|}
\hline Theatrical performance factors & $\begin{array}{l}\text { Factor } \\
\text { loading }\end{array}$ & Eigenvalue & $\begin{array}{l}\text { Variance } \\
\text { explained }(\%)\end{array}$ & $\begin{array}{l}\text { Reliability } \\
\text { coefficient }\end{array}$ & Communalities \\
\hline Factor 1- Performance & & 16.727 & 22.011 & .944 & \\
\hline 6. Professional performers & .777 & & & & .789 \\
\hline 7. Good coordination among performers & .722 & & & & .777 \\
\hline 5. Performers show emotion & .718 & & & & .727 \\
\hline 8. Dancing & .704 & & & & .698 \\
\hline 4. Costumes & .702 & & & & .666 \\
\hline 9. Music and songs & 674 & & & & .692 \\
\hline 12. Stage decoration & 604 & & & & .731 \\
\hline 3. Atmosphere of the performance & .601 & & & & .606 \\
\hline 10. Loud sounds & .584 & & & & .650 \\
\hline 2. Performance is special and unique & .519 & & & & .523 \\
\hline 11. Interpretation and introduction by the host & .511 & & & & .595 \\
\hline Factor 2- Venue Environment & & 2.379 & 19.198 & .932 & \\
\hline 19. Comfortable seating & .817 & & & & .834 \\
\hline 20. Vision of the performance & .762 & & & & .760 \\
\hline 22. Moderate temperature in the venue & .762 & & & & .739 \\
\hline 21. Clean air & .748 & & & & .814 \\
\hline 18. Cleanliness of the venue & .705 & & & & .767 \\
\hline 24. Behavior of other audience members & .581 & & & & .625 \\
\hline \multirow{2}{*}{\multicolumn{6}{|c|}{$\begin{array}{l}\text { (Standing up, and taking pictures during the } \\
\text { performance) }\end{array}$}} \\
\hline & & & & & \\
\hline 23. Safety and security of the venue & .500 & & & & .699 \\
\hline Factor 3- Service & & 1.344 & 16.643 & .938 & \\
\hline 30. Competent staff & .779 & & & & .831 \\
\hline 29. Staff who are willing to help & .770 & & & & .863 \\
\hline 28. Friendly staff & .766 & & & & .875 \\
\hline 26. Service quality of the staff & .686 & & & & .816 \\
\hline 31. Value for money of the price charged & 633 & & & & .637 \\
\hline 27. Suitable duration of the performance & .618 & & & & .684 \\
\hline Factor 4- Stage Facilities & & 1.073 & 11.575 & .869 & \\
\hline 14. Scale of the stage & .776 & & & & .749 \\
\hline 13. Background scenery or screen & .774 & & & & .784 \\
\hline 15. Water and a waterfall on the stage & .602 & & & & .686 \\
\hline 16. Lighting & .514 & & & & .643 \\
\hline
\end{tabular}

Note: $\mathrm{KMO}=.931$; Bartlett's Test of Sphericity: chi-square $=5632, \mathrm{df}=465, \mathrm{p}<.000$ 
Table 4 Comparison of theatrical performance factors

\begin{tabular}{llll}
\hline Factor & Factor Name & Factor Mean & Ranking \\
\hline Factor 4 & Stage Facilities & 6.42 & 1 \\
Factor 1 & Performance & 6.32 & 2 \\
Factor 3 & Service & 5.87 & 3 \\
Factor 2 & Venue Environment & 5.72 & 4 \\
\hline
\end{tabular}


Table 5 Regression results of tourist overall satisfaction level based on factor scores

\begin{tabular}{|c|c|c|c|c|c|}
\hline $\begin{array}{l}\text { Dependent variable } \\
\text { Independent variables }\end{array}$ & \multicolumn{5}{|c|}{ Tourist overall satisfaction with theatrical performance } \\
\hline \multicolumn{6}{|l|}{ Goodness-of-fit } \\
\hline Multiple $\quad R=.643$ & & & & & \\
\hline \multicolumn{6}{|l|}{$\mathrm{R}^{2}=.414$} \\
\hline \multicolumn{6}{|l|}{ Adjusted $\mathrm{R}^{2}=.400$} \\
\hline \multicolumn{6}{|l|}{ Standard error $=.777$} \\
\hline Analysis of variance & \multicolumn{2}{|c|}{ Sum of squares } & df & \multicolumn{2}{|c|}{ Mean square } \\
\hline Regression & \multicolumn{2}{|c|}{73.683} & 4 & \multicolumn{2}{|c|}{18.421} \\
\hline Residual & \multicolumn{2}{|c|}{104.368} & 173 & \multicolumn{2}{|c|}{.603} \\
\hline \multicolumn{6}{|l|}{ F ratio $=34.594$} \\
\hline \multicolumn{6}{|l|}{ Significance $=.000$} \\
\hline \multicolumn{6}{|l|}{ Variable in the equation } \\
\hline Independent variable & B & Std. Error & Beta & $\mathrm{t}$ & Sig. \\
\hline Factor 1 Performance & .349 & .058 & .353 & 6.056 & .000 \\
\hline Factor 2 Venue Environment & .344 & .057 & .349 & 5.997 & .000 \\
\hline Factor 3 Service & .369 & .058 & .368 & 6.321 & .000 \\
\hline Factor 4 Stage Facilities & .183 & .058 & .184 & 3.167 & .002 \\
\hline (Constant) & 6.071 & .058 & & 104.275 & .000 \\
\hline
\end{tabular}


Table 6 Differences in satisfaction towards the theatrical performance factors by demographic and travel characteristics

\begin{tabular}{llccl}
\hline Theatrical performance factor & Demographics & $\mathrm{t}$ value & $\mathrm{Sig}$ & Differences and means \\
\hline Factor 1 Performance & Gender & -0.218 & .048 & Male $>$ Female $(6.23>6.37)$ \\
\hline Factor 2 Venue Environment & Gender & -1.579 & .014 & Male $>$ Female $(5.83>5.56)$ \\
\hline Factor 3 Service & Age & 3.041 & .019 & $19-29>40-49(6.11>5.35)$ \\
& Marital status & 3.293 & .024 & Single $>$ Married $(6.08>5.64)$ \\
\hline
\end{tabular}

